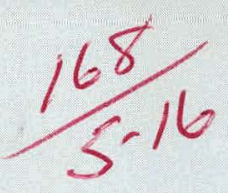

\title{
EXPLOSIBILITY TEST FACILITY FOR POWDERS
}

J. D. Lore

J. E. Miller

\section{UNION} CARBIDE
OAK RIDGE Y-12 PLANT

OAK RIDGE. TENNESSEE 


\section{DISCLAIMER}

This report was prepared as an account of work sponsored by an agency of the United States Government. Neither the United States Government nor any agency Thereof, nor any of their employees, makes any warranty, express or implied, or assumes any legal liability or responsibility for the accuracy, completeness, or usefulness of any information, apparatus, product, or process disclosed, or represents that its use would not infringe privately owned rights. Reference herein to any specific commercial product, process, or service by trade name, trademark, manufacturer, or otherwise does not necessarily constitute or imply its endorsement, recommendation, or favoring by the United States Government or any agency thereof. The views and opinions of authors expressed herein do not necessarily state or reflect those of the United States Government or any agency thereof. 


\section{DISCLAIMER}

Portions of this document may be illegible in electronic image products. Images are produced from the best available original document. 
Printed in the United States of America. Available from National Technical Information Service

U.S. Department of Commerce

5285 Port Ruyal Road, Springfield, Virginia 22151

Price: Printed Copy $\$ 3.00$; Microfiche $\$ 0.95$

This report was prepared as an account of work sponsored by the United States Government. Neither the United States nor the United States Atomic Energy Commission, nor any of their employees, nor any of their contractors, subcontractors, or their employees, makes any warranty, express or implied, or assumes any legal liability or responsibility for the accuracy, completeness or usefulness of any information, apparatus, product or process disclosed, or represents that its use would not infringe privately owned rights.

Reference to a company or product name does not imply approval or recommendation of the product by Union Carbide Corporation or the U S Atomic Energy Commission to the exclusion of others that may meet specifications. 


\title{
EXPLOSIBILITY TEST FACILITY FOR POWDERS
}

\author{
J. D. Lore \\ J. E. Miller
}

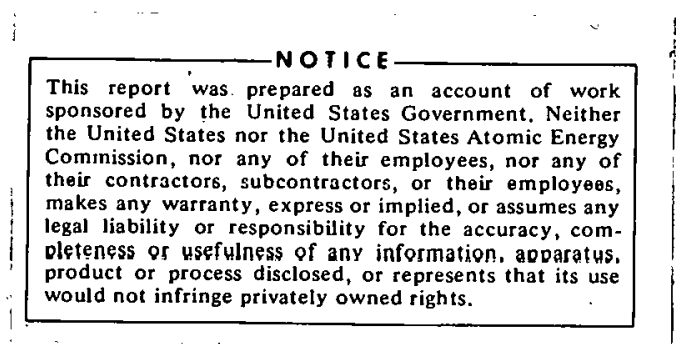

Oak Ridge Y-12 Plant

P.O. Box Y, Oak Ridge, Tennessee 37830

Date Issued - May 4, 1973

Prepared for the U.S. Atomic Energy Commission Under U.S. Government Contract W.7405eng.26 
THIS PAGE

\section{WAS INTENTIONALLY LEFT BLANK}




\begin{abstract}
A laboratory test facility has been developed for assessing the ignitability and explosibility of powder disseminations. The occurrences of frequently unforeseen powder fires and explosions during production operations and in the course of laboratory handling, prompted its development. General guidelines regarding the equipping of the facility were obtained from the United States Bureau of Mines. Typical application of the facility to powdered aluminum and magnesium was investigated.
\end{abstract}




\section{CONTENTS}

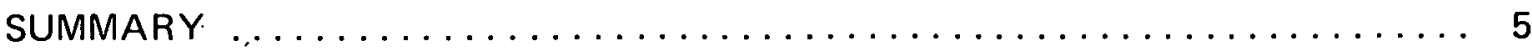

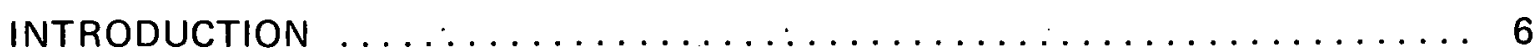

TEST FACILITY FOR POWDER EXPLOSIBILITY STUDIES $\ldots \ldots \ldots \ldots \ldots \ldots \ldots$

United States Bureau of Mines Support $\ldots \ldots \ldots \ldots \ldots \ldots \ldots \ldots \ldots \ldots \ldots$

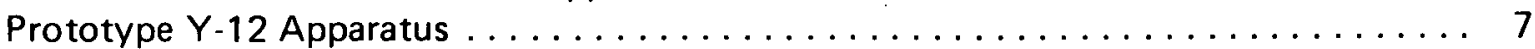

Limitations ............................ 7

Neteded Design Improvements $\ldots \ldots \ldots \ldots \ldots \ldots \ldots \ldots \ldots \ldots \ldots \ldots \ldots$

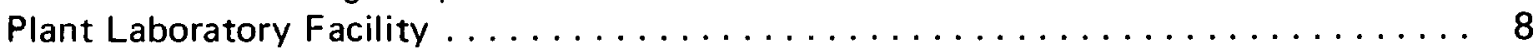

Basic Features ............................ 8

Functional Explanation for the Equipment $\ldots \ldots \ldots \ldots \ldots \ldots \ldots \ldots \ldots$

Typical Test Results . . . . . . . . . . 11

Findings for Aluminum and Magnesium Powders . . . . . . . . . . . 11

Recommendations for Safe Handling . . . . . . . . . . . . . . . 13

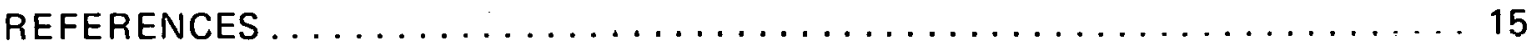

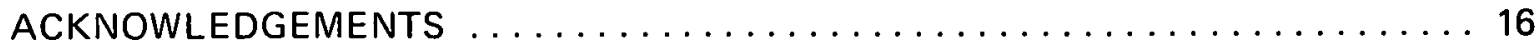

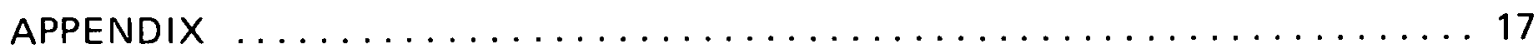

Detailed Procedures for Powder Explosibility Determinations . . . . . . . . . 17

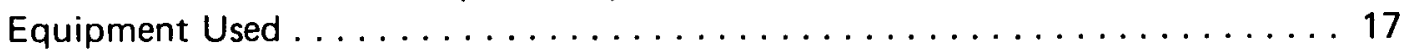

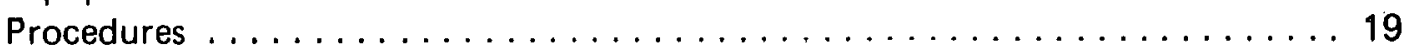

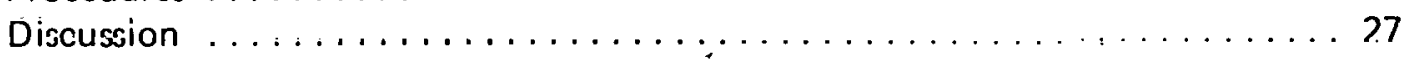




\section{SUMMARY}

A facility has been established to evaluate and alleviate the ignitability/explosibility hazards of dispersed powders. The test apparatus is remotely operated and situated in a glove-box enclosure. Testing and ambient environmental surroundings are strictly controlled to avoid inadvertent reactions and to maintain sample integrity prior to testing. (a) After conducting certain classification tests according to United States Bureau of Mines criteria, testing in depleted oxygen atmospheres was useful for establishing guidelines for safe handling.

(a) This unique capacity prevents surface oxidation, thus permitting simulation of conditions existing during production operations which generate powder. 


\section{INTRODUCTION}

Hazards of dust explosions arising in the manufacturing and processing industries have long been recognized. Until about 1943, no organization had engaged in testing development for evaluating such hazards beyond what was necessary to alleviate their individual problems. At this time, the United States Bureau of Mines (Bur Mines) published the first compilation of explosibility results comprising some fourteen metallic elements and two alloys. (1) The findings were for tests of ignitability and explosibility originally developed by the Bureau for the assessment of coal dust. By 1964, a total of 313 elemental metals, alloys, catalysts, and ores had been evaluated and reported. (2)

The Oak Ridge $Y-12$ Plant $(b)$ is involved in powder metallurgical programs which require handling finely divided materials. Most of these material types are potentially hazardous with respect to ignitability and explusibility; and, gencrally, the extent of their susceptibilities to such behavior is not precisely known. In $196 \%$, after an exterısive fire/explosion in a filter house, a decision was made to develop laboratory test equipment for evaluating explosibility hazards. Consulation with the Bur Mines at their Bruceton, Peninsylvania laboratories led to the construction of an apparatus fashioned after that developed and refined in the course of their research. (3) Further refinements to the $Y-12$ apparatus were made, based on testing development and arising needs between 1967 - 1970. In mid 1971, installation of more sophisticated equipment at the Plant Laboratory was completed. The purpose of this report is to generally describe the laboratory facility, the instrumental capabilities, and to report some recent applications.

(b) Operated for the US Atomic Energy Commission by the Union Carbide Corporation's Nuclear Division. 


\section{TEST FACILITY FOR POWDER EXPLOSIBILITY STUDIES}

\section{UNITED STATES BUREAU OF MINES SUPPORT}

Techniques for evaluating the ignition and explosion hazards of finely divided materials have evolved over the years; based, primarily, upon the practical needs of engineers. Reliable guidelines for safe and efficient operation have been sought rather than the absolute assessment of reactivity, based upon thermodynamic criteria. The adopted experimental methods (usually some type of batch testing) yield numerical results which are evaluated empirically by reference to data for some material with a recognized hazard.

The most definitive and, no doubt, reliable scheme for defining explosive limits has been developed by the Bur Mines. (3) As noted previously, extensive testing development and materials evaluation have been conducted at the Bureau's Health and Safety Research and Testing Center, Bruceton, Pennsylvania. Based upon several pertinent tests, a so-called "explosibility index" is obtained to rate the hazard of a powder. Computation of this index involves determination of the powder's ignition temperature, minimum ignition energy, maximum explosion pressure, and rate of pressure rise under certain standardized conditions. Comparison with similar findings for a particular grade of Pittsburgh seam coal dust yields a numerical value usually ranging from 0.1 to 10 . Adjective ratings (eg, none, weak, moderate, strong, and severe) for the implied hazard are then applied, based upon the magnitude of the index. The Bur Mines own appraisal of the Index of Explosibility is aptly put, namely: "This index is not derived from theoretical considerations, but is consistent with observations in research and from experience".(3) Certainly, this approach serves a useful purpose in regard to appraising the relative sensitivity of an unknown material compared to the well-characterized Bur Mines standard coal. The objective at the Oak Ridge $Y$-12 Plant was not so definitive, however, such that this degree of data correlation was required. Needs at $Y-12$ dictated that, while some classification method for sensitivity was desirable, the overriding requirement was the curtailment of powder sensitivity. Based on further discussions with the Bureau, it was decided to utilize a single apparatus for an initial classification of the material sensitivity, with appropriate modification to facilitate ignition/explosion curtailment by installing a depleted oxygen environment.

\section{PROTOTYPE $Y-12$ APPARATUS}

\section{Limitations}

The initial Y-12 apparatus was a facsimile of the Bur Mines Hartmann apparatus, (3) and it functioned satisfactorily for preliminary classification of powder sensitivity. Tests included the limiting (lowest) energy and concentration requirements for ignition and explosion of a dispersed dust cloud. The prototype apparatus was not suitable for efficiently handling or testing materials in a controlled environment. Instrumental controls were cumbersome and did not adapt to routine testing. With the existing laboratory sample storage facility, maintenance of the sample's chemical integrity and, thus, preservation of its maximum ignition sensitivity was, at best, questionable. Safe handling of those potentially pyrophoric materials was difficult, if not impossible. Powders with high respiratory toxicities and radioactive materials, particularly if disseminated in the ambient air in the course of testing. posed still other problenis. 


\section{Needed Design Improvements}

Accordingly, the necessary design improvements and consideration of potential safety hazards dictated that the apparatus be housed in a leak-tight enclosure with an inert environment and operated remotely from an external control panel. Provisions were also required for suppression and/or physical containment of the explosion products (heat, light, noise, extremely rapid pressure development, and particulate matter).

\section{PLANT LABORATORY FACILITY}

Design of the instrument and containment facility, as depicted schematically in Figure 1 , was a joint effort on the part of the Y-12 Laboratory Development and Environmental Enginecring Departments.

\section{Basic Features}

Figure 2 gives an overall view of the facility. The main control panel is shown at the lefi. It operates the test apparatus which is situated in the explosive test box. The sample-preparation box is shown to the right, adjoining the test box through an airlock. A continuous argon flow is conducted through the boxes at a rate sufficient to maintain the boxes at a slightly positive pressure of 0.4 to 0.7 inch of water. The environmental moisture levels in the boxes and airlock are continuously monitored with appropriately placed aluminum oxide sensors, and are read out on a controller and/or strip-chart recorder as dew points. An automatic gas collection system provides samples from these locations to an electrochemical oxygen analyzer. Atmuspheric oxygen content is read out on a strip-chart recorder directly in parts per million (ppm). Dew points (DP) of $-50^{\circ} \mathrm{C}$ (corresponding to about $40 \mathrm{ppm} \mathrm{H} \mathrm{H}_{2} \mathrm{O}$ ) and oxygen levels of slightly less than $20 \mathrm{ppm}$ can be maintained under optimum conditions. In routine operating circumstances, a $-40^{\circ} \mathrm{C} \mathrm{DP}\left(100 \mathrm{ppm} \mathrm{H}_{2} \mathrm{O}\right)$ and $500 \mathrm{ppm}$ oxygen can be maintained. Moisture and oxygen alarm systems with flashing lights and an audible annunciator indicate when these preset operating limits are exceeded. Gaseous explosibility test environments of variable oxygen contents as low as 0.1 percent by volume in argon are provided, as required from a dynamic diluting system.

Safety features include blowout panels on the test box which vent to the atmosphere through HEPA filters. The slide valve (Figure 1, Item 7) is equipped with an explosion disc designed to rupture in the event of a premature explosion or valve failure during a test. All effluent materials from the test box and sample-preparation box are also filtered through HFPA filters.

\section{Functional Explanation of the Equipment}

In order to understand the functional nature of the facility, a typical operational sequence may be described briefly. A detailed methodology report occupies the Appendix. Upon receipt of a powder sample at the Plant Laboratory, the material is immediately placed in the sample-preparation box so that its as-received integrity may be maintained prior to testing. Aliquots are prepared for other tests to establish other relevant physical properties (such as those reported in Table 1) which may contribute to its explosive character. Weighed aliquots for the explosibility determination are passed through the airlock to the test box 


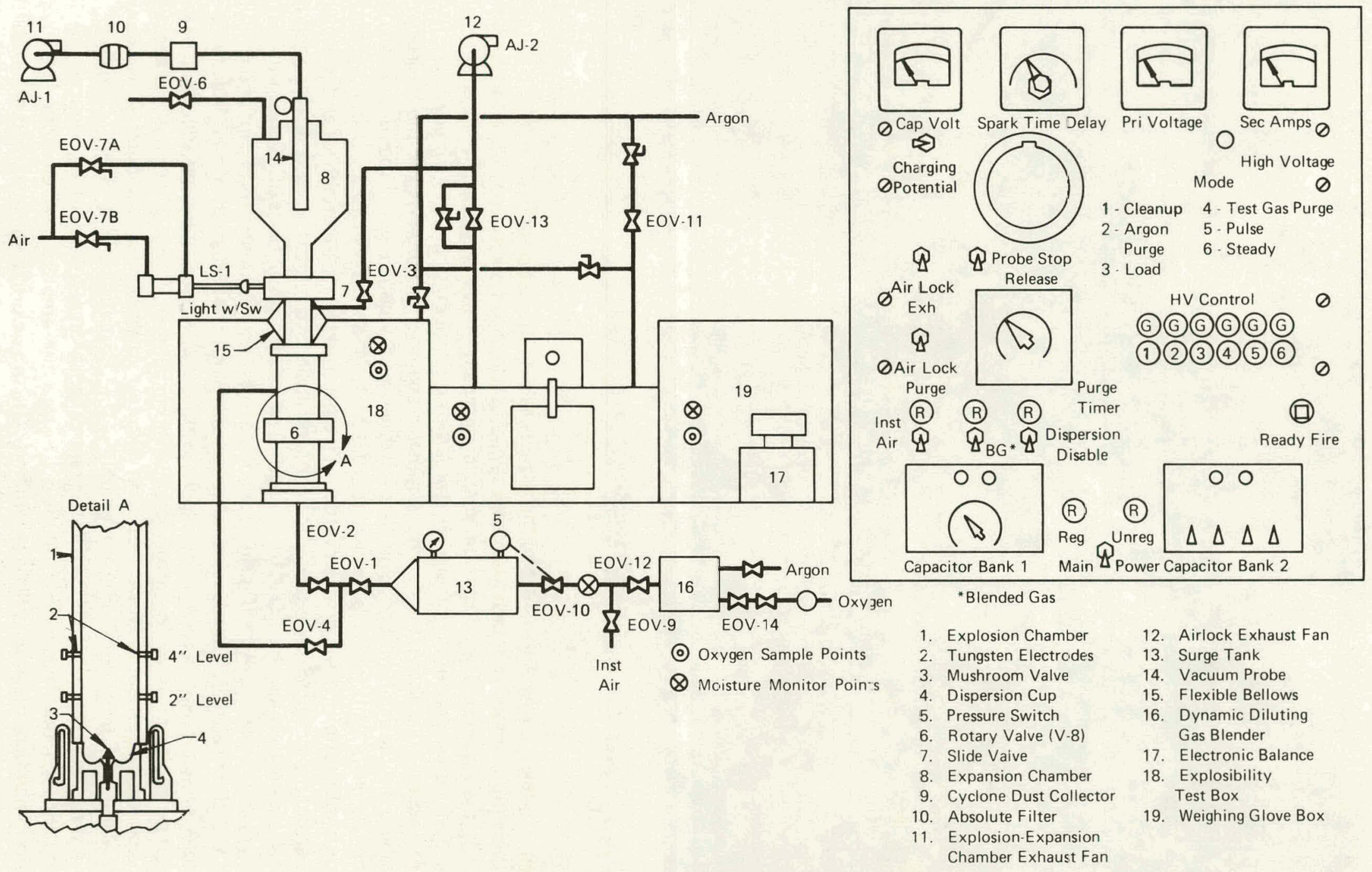

Figure 1. PRINCIPAL COMPONENTS OF THE EXPLOSIBILITY APPARATUS. 


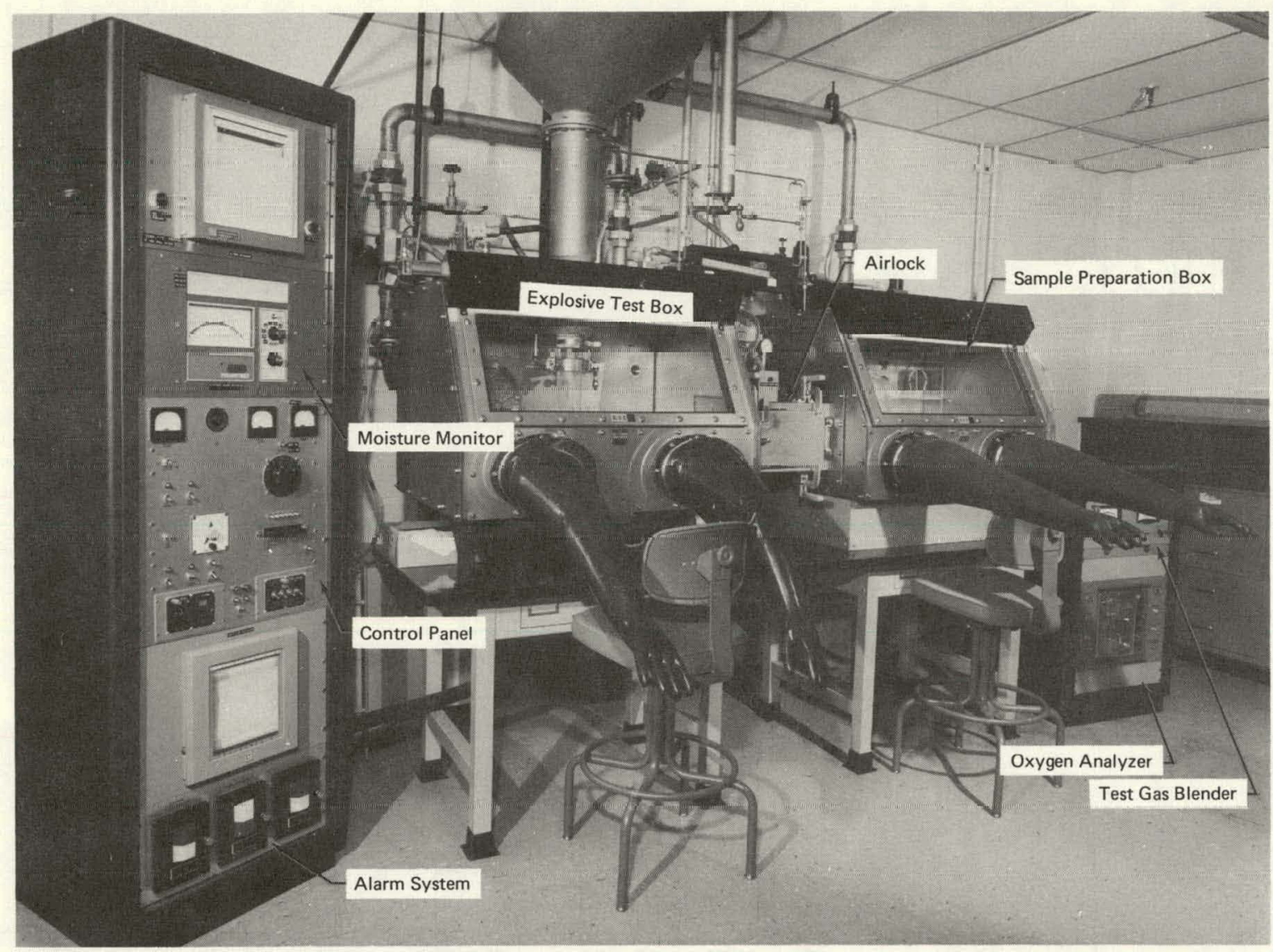

Figure 2. EXPLOSIBILITY TEST FACILITY.

139634

just prior to testing (see Figures 1 and 3). After selecting the Load mode (Mode 3, Figure 1), the explosion chamber is detached to expose the bowl-shaped dispersion cup into which the sample is then placed. The mushroom-shaped dispersion valve is opened to an appropriate setting that varies, depending on which test is being conducted, and the rotary valve ( $\mathrm{V}-8$; Item 6, Figure 1) is then closed. The explosion chamber is purged with the desired test atmosphere in Mode 4 (either a blend of oxygen and argon or with instrument air) by opening the electrically operated valves (EOV-10,-1, -4, and -3; Figure 1). Using this route, premature disruption of the dust is avoided. The electrode leads are attached, and either the Pulse for energy or the Steady mode for concentration or depleted oxygen tests is selected. Dust dispersion through the EOV $-10,-1$, and -2 route by a single blast of gas from the surge tank (typically pressurized to $10 \mathrm{psig}$ ), sparking across the preset electrode gap, and opening of the V-7 slide valve are coordinated automatically with the actuation of the "Ready-Fire" button. A typical result is seen in Figure 4. In this case, an aluminum powder explosion is shown. The explosion is vented into the expansion chamber (Figure 3) so that proliferation of its undesirable products is avoided. The Cleanup mode is next employed. The vacuum probe is lowered into the explosion chamber, and residual dust is conveyed through a cyclone dust collector to an HEPA filter by an exhaust fan (AJ-1; Item 11, Figure 1). After stepping through the Argon Purge mode to restore the ambient test environment to the explosion chamber, the test cycle is completed. The procedure is repeated, and explosibility 
limits are established by repetitive tests that are judged on a go or no-go basis according to Bur Mines evaluation criteria.(3)

Table 1

PERTINENT PHYSICAL PROPERTIES AND EXPLOSIBILITY RESULTS

\begin{tabular}{|c|c|c|c|c|c|c|c|c|c|}
\hline \multirow{2}{*}{$\begin{array}{c}\text { Screen } \\
\text { Size Range } \\
\text { (mesh) }\end{array}$} & \multicolumn{3}{|c|}{$\begin{array}{c}\text { Coulter Size } \\
\text { Distribution } \\
(\%<\text { given } \mu \mathrm{m})\end{array}$} & \multirow{2}{*}{$\begin{array}{c}\text { Surface } \\
\text { Area }(1) \\
\left(\mathrm{m}^{2}-\mathrm{gm}^{-1}\right)\end{array}$} & \multirow{2}{*}{$\begin{array}{l}\text { Density (2) } \\
\left(\mathrm{gm}-\mathrm{m}^{-3}\right)\end{array}$} & \multirow{2}{*}{$\begin{array}{l}\text { Oxygen } \\
\text { Content (3) } \\
(p p m)\end{array}$} & \multirow{2}{*}{$\begin{array}{c}\text { Minimum } \\
\text { Energy (4) } \\
\text { (joules) }\end{array}$} & \multirow{2}{*}{$\begin{array}{l}\text { Lower } \\
\text { Explosion } \\
\text { Limit }(5) \\
\left(\mathrm{gm}^{-1}\right)\end{array}$} & \multirow{2}{*}{$\begin{array}{l}\text { Limiting } \\
\text { Oxygen } \\
\text { Content }(6) \\
\text { (\% by vol) }\end{array}$} \\
\hline & 90 & 50 & 10 & & & & & & \\
\hline & & & & & Aluminum & & & & \\
\hline$-230+270$ & 67.0 & 56.5 & 43.0 & 0.167 & 2.77 & 3,600 & 10.4 & 0.22 & 7.5 \\
\hline$-270+325$ & 62.5 & 51.7 & 40.5 & 0.198 & 2.74 & 3,300 & 9.6 & 0.20 & 8.0 \\
\hline$-325+400$ & 50.0 & 42.0 & 31.0 & 0.195 & 2.76 & 3,700 & 4.0 & 0.14 & 7.5 \\
\hline$-400+500$ & 45.0 & 36.0 & 25.0 & 0.219 & 2.75 & 3,900 & 0.80 & 0.05 & 6.0 \\
\hline \multirow{2}{*}{$\begin{array}{l}-500 \\
\text { (7) }\end{array}$} & 33.0 & 26.7 & 19.8 & 0.237 & 2.78 & 3,800 & 0.75 & 0.04 & 6.0 \\
\hline & 16.7 & 11.7 & 6.5 & 0.424 & 2.76 & 5,900 & 0.40 & 0.04 & 6.0 \\
\hline \multicolumn{10}{|c|}{ Magnesium } \\
\hline+170 & & & & 0.162 & 1.75 & 8,500 & 11.2 & 0.14 & 5.0 \\
\hline$-170+200$ & & & & 0.148 & 1.70 & 10,020 & 3.2 & 0.09 & 3.0 \\
\hline$-200+270$ & 76.5 & 64.0 & 35.0 & 0.228 & 1.71 & 11,400 & 1.6 & 0.06 & 2.5 \\
\hline$-270+325$ & 57.9 & 46.2 & 36.0 & 0.337 & 1.73 & 14,200 & 0.30 & 0.04 & 1.5 \\
\hline$-325+400$ & 52.0 & 41.7 & 31.1 & 0.403 & 1.78 & 15,900 & 0.25 & 0.03 & 1.5 \\
\hline-400 & 40.1 & 31.3 & 19.4 & 0.503 & 1.73 & 25,400 & 0.25 & 0.03 & 1.5 \\
\hline
\end{tabular}

(1) BET krypton adsorption.

(2) Helium displacement.

(3) Neutron activation.

(4) The smallest capacitor discharge spark energy required to produce flame propagation four inches or longer in a dust cloud of optimum concentration.

(5) The smallest sample weight which may be ignited by induction spark to produce a low-ordered explosion of an established magnitude within an enclosed volume.

(6) That highest environmental oxygen content at which explosion or rapid combustion does not occur in four of four trials using the optimum dispersed dust concentrations and a continuous induction spark in a predominantly argon atmosphere.

(7) Collector fines from Vortex C-1 classifier.

\section{TYPICAL TEST RESULTS}

\section{Findings for Aluminum and Magnesium Powders}

The utility of these tests may be illustrated by considering some specific results for two materials-aluminum and magnesium. The as-received powders were screened to provide various size fractions that could be preferentially employed for this application. Physical properties of the resulting samples and explosibility results are tabulated in Table 1. Minimum-energy values serve as an indicator of the powder-ignition sensitivity to relatively weak igniting sources such as electrostatically generated sparks. All -270 mesh and finer magnesium samples were readily ignitable at relatively low energies. Only the -400 mesh aluminum fractions ignited at energies that were sufficiently low to indicate a serious hazard from such phenomena. The lower explosion limit (LEL) establishes the smallest dispersed dust concentration that will, by the arbitrary definition (Table 1), be considered as 


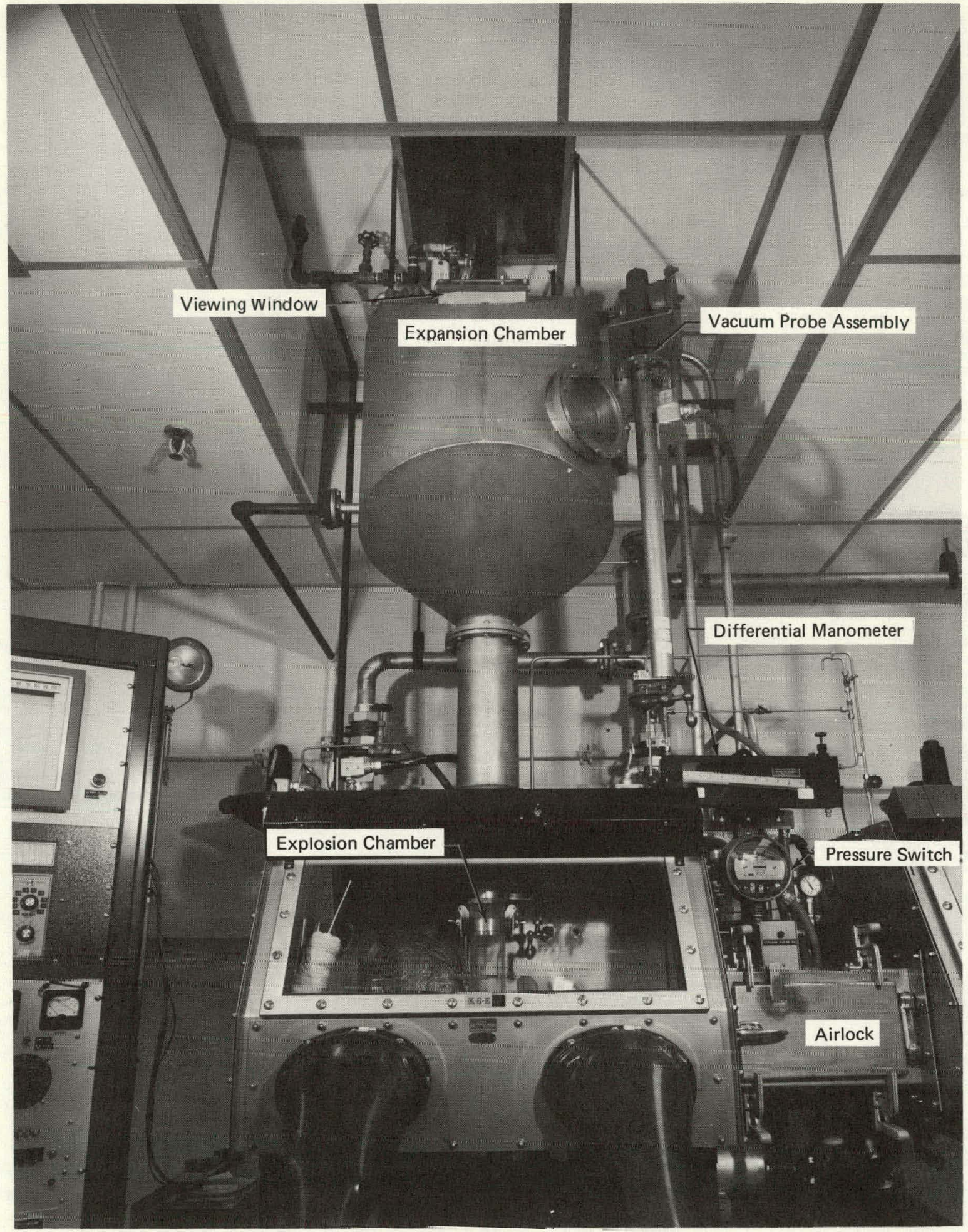

139636

Figure 3. EXPLOSIBILITY TEST BOX. 


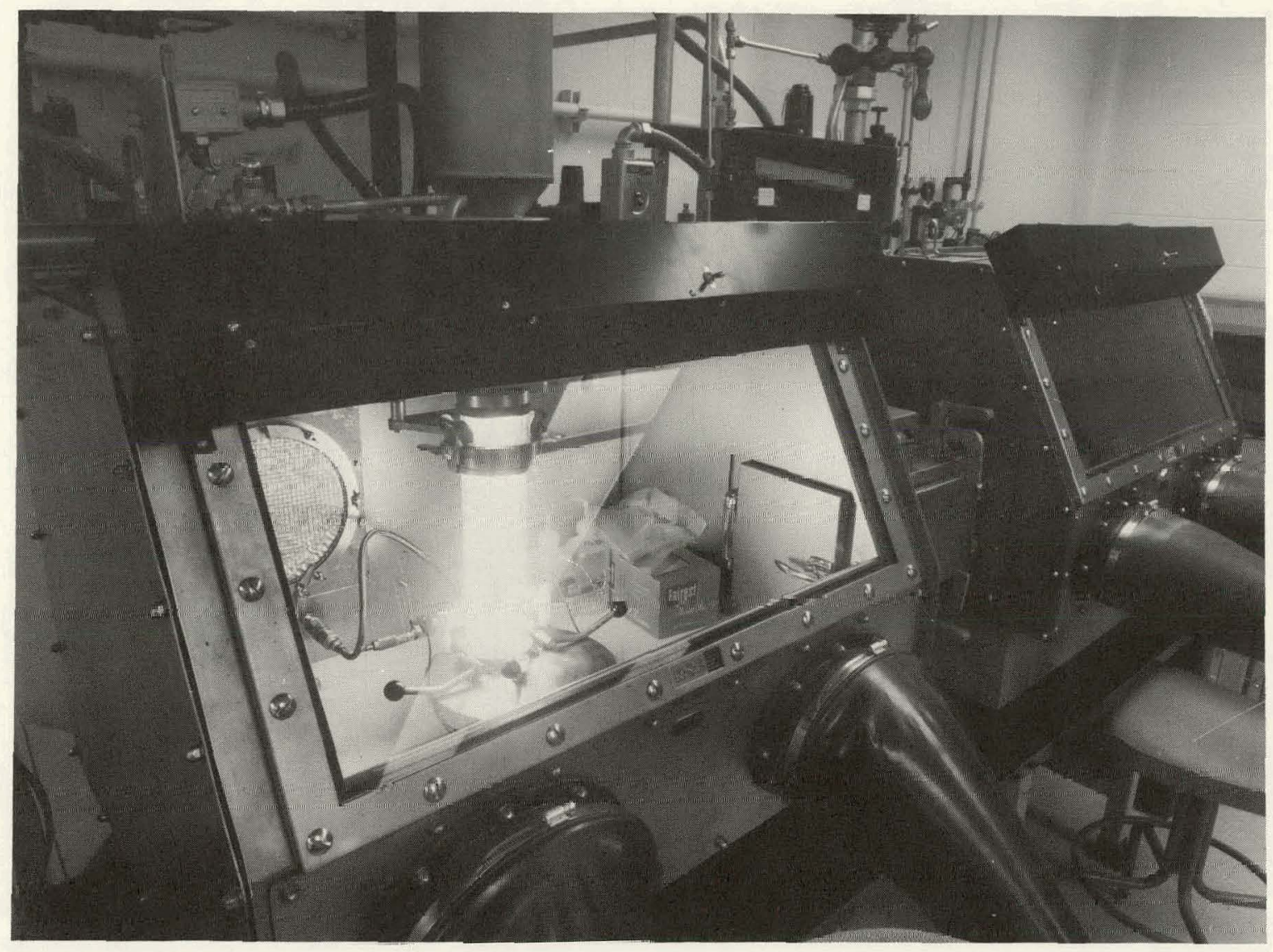

Figure 4. ALUMINUM POWDER EXPLOSION.

139642

explosive upon the application of a strong igniting source. Smaller concentrations may be combustible, but will not sustain an explosion. With regard to the aluminum's LEL, the -400 mesh fractions were extremely reactive to the strong induction spark and typically exhibited rapid ignition and flame propagation. All magnesium samples were in this category and should be handled with great care.

\section{Recommendations for Safe Handling}

The limiting oxygen content ( $L O C$ ) determined for oxygen-argon blends ranged from 6.0 to 8.0 volume percent oxygen for the aluminum fractions and from 1.5 to 5.0 volume percent for the magnesium fractions. Aluminum processing industries typically install a 50 percent safety factor upon such results and would accordingly operate at oxygen concentrations not exceeding 3 to 4 volume percent with aluminum and 0.75 to 2.5 percent with magnesium, based on these findings. (4) At $\mathrm{Y}-12$, this factor has been arbitrarily adopted. Thus, these exemplary findings for aluminum and magnesium do indicate a potential hazard which may, however, be surmounted by operating in a controlled environment. 
Many processes at the Oak Ridge Y-12 Plant employ potentially hazardous materials. The commitment of resources necessary to define and curtail the associated ignition/explosion hazards, while substantial, has been demonstratively worthwhile from the standpoint of safety. 


\section{REFERENCES}

(1) Hartmann, I., Nagy, J., and Brown, H.; "Inflammability and Explosibility of Metal Powders", Bureau of Mines Report of Investigations, 3722 (1943).

(2) Jacobson, M., Cooper, A., and Nagy, J.; "Explosibility of Metal Powders", Bureau of Mines Report of Investigations, 6516 (1964).

(3) Dorsett, H., Jacobson, M., Nagy, J., and Williams, R.; “Laboratory Equipment and Test Procedures for Evaluating Explosibility of Dusts", Bureau of Mines Report of Investigations, 5624 (1960).

(4) Brandt, J. L.; Personal Communication; Alcoa Research Laboratories; May 18, 1967. 


\section{ACKNOWLEDGEMENTS}

The authors wish to thank R. W. Jackson and R. R. Stephens of the Instrument and Control Engineering Section who provided electrical design criteria for the facility. C. L. Scalf, Environmental Engineering, performed most of the detailed mechanical design work. W. F. Carden, Plant Laboratory, who is in charge of explosibility tests, and his associates, W. T. McBryde, J. D. Caylor, C. Cook, Jr, and W. Garland, all contributed significantly to this project. B.W. Moore, Wallace Humphrey, and H.C. Smith of the Area 5, B-1 Maintenance Section provided invaluable trouble-shooting and maintenance support. Lastly, a word of thanks to John Nagy, Chief, Branch of Dust Explosions, Health and Safety Research Center, Bureau of Mines, Bruceton, Pennsylvania and his associates A. R. Cooper and Earl Seiter who essentially made this development possible by furnishing their expertise and detailed design criteria for the Hartmann apparatus. 


\section{APPENDIX}

\section{DETAILED PROCEDURES FOR POWDER EXPLOSIBILITY DETERMINATIONS}

\section{Equipment Used}

Applicator - Q tip.

Blowout Diaphragm - Filter paper, $11 \mathrm{~cm}$, Eaton-Dikeman 615.

Brushes, Disposable - Quill, "camel's hair".

Brush, Tooth

Chamber Cleaning Device - Six $21 / 2$-inch polishing wheels attached to a 24-inch length of $1 / 8$-inch welding rod.

Cleaner. Varııum - Acceccorico for expansiuiiı cl laınber, brüusti hose, and rubber tools.

Coupler, Quick - 1/4 NPT and nipple.

Cylinder, Double Connection - 150-cc capacity, Hoke 4LD150.

Electrodes, Tungsten - 0.032-inch-diameter, 3 31/32-inch-long, pointed rods. (c)

Foil, Aluminum - Slide valve blowout diaphragm, 8 × 8 × 0.001 inches.

\section{Gap Setting Tools •}

13-inch-long, 1/8-inch-diameter rod

13-inch-long, 3/16-inch-diameter rod

13-inch-long, 1/2-inch-diameter rod

Each tool is mounted in a 3-inch length of Teflon rod.

Gloves, Glove Box .

Light Weight

Medium Weight

Gloves, Undertaker's Type'

(c) Fabricated from tungsten bar. (Advise Stores clerk to cut bar in 5-inch lengths and not to bend this item in preparation for shipping.) 
Gloves, Rubber -

Gasket, Oval Ring :

Bellows - EM-67197 - Parker 2-339, Teflon.

Explosion Chamber-EM-67197-Parker 2-001, neoprene and Parker 2-344, neoprene.

Oxygen Analyzer Cell - Parker 2-234, neoprene.

Oxygen Analyzer Vent - Parkcr 2-006.

Rotary Valve - EIVI-67162 - Palkel 2-014, butyl rubber and Parker 2-172, neoprene; EM-67197 - Parker 2-238, neoprene.

Slide Valve - EM-67197 - Parker 2-1, neoprene; EMI-6/201 - Parker 2-012, neoprcric and Parker 2-234, Teflon.

Vacuum Probe - EM-67197 - Parker 2-018, butyl rubber.

Goggles, Welders - Shade 5.

Grease, Silicone - For all gasket seals except for the oxygen analyzer.

Lubricant -

Moly-B for hand-crank mechanism.

Graphite Jet 4 for lower expansion chamber clamps.

Micrometer Head - For electrode assembly.

Mirror, Adjustable $-21 / 8 \times 31 / 2$ inches.

Perforator Tool-5-inch-long, 1/16-inch-diameter welding rod mounted in a 2-inch-long Teflon rod.

Powder Paper - $3 \times 4$ 3/4-inch Size 3 tli Lilly.

Pump, Air - 115 V, 60 Hz, 1,700 rpm, Neptune Model 18-309X, 22702.

Regulator - FH60 Airpak filter-rcgulator combination, 1/4-inch NPT.

Scoopula - Stainless steel.

Spatula - Stainless steel. 
Standards -

Pittsburgh pulverized coal dust. US Bureau of Mines Grade 2551, 95 percent through Size 200 sieve.

Aluminum dust, atomized, commercial-purity fines, 100 percent through 200 sieve.

Aluminum dust, atomized, 100 percent through Size 200 sieve, Alcoa Grade 123.

Aluminum dust, extra fine lining powder, 100 percent through Size 325 sieve. Alcoa Grade 422.

Tubing: Methyl methacrylate, clear, 3.25-inch OD $\times 0.25$-inch wall $\times 12$ inches long.

Tweezers, Utility .

Valve, Check $-1 / 3$ to 1 psig opening pressure, $1 / 4$ inch.

Valve Insert Extraction Tool - Pin vice attached to Size 2-56 bottom-type tap (for removal of press-fitted mushroom valve insert).

\section{Procedures}

Establishing the Optimum Sample Weight, Time Delay, and Dispersing Pressure for the Minimum Energy Determination - Steps in this procedure are:

1. Close the main Power switch and allow the control console about a five-minute warmup time (Figure 1). Engage Pushbutton 3 to enter the Load mode. Meanwhile, proceed with Steps 2 - 6 .

2. Weigh 1.0, 2.0, and 3.0-gram samples into plastic vials; and, after conducting a ten-minute airlock purge, transfer the aliquots to the test box.

3. Secure the electrodes at the 4-inch level; adjust the electrode spark gap to $1 / 8$ inch. Using a short section of $1 / 4$-inch-ID rubber tubing, unthread the mushroom dispersion valve by four counterclockwise 360-degree rotations from its fully inserted position, making sure that the stem and not the cap is unthreading. Set the dispersing pressure.at 10 psig.

4. Release the quick coupler at the explosion chamber connection and remove the braided steel hose. Unlatch the lower exnansion chamber clamps alid lurn the handcrank mechanism clockwise until the bellows assembly is sufficiently elevated to clear the top sealing flange of the explnsinn chamber. Unlatch the rotary valve locking clamps and detach the explosion chamber from the dispersion cup. Spread, as uniformly as possible, a. 1.0-gram sample in the dispersion cup, leaving vacant the area within a $1 / 16$-inch radius of the periphery of the mushroom valve.

5. Close the dispersion cup rotary valve, attach the explosion chamber, and secure the locking slamps. Insert the extended tips of each of the electrodes into the bore of the 
lead connectors. Place the blowout diaphragm between the top sealing flange of the explosion chamber and the lower bellows assembly sealing surface, and lower the assembly by counterclockwise rotation of the handcrank mechanism. Secure the lower expansion chamber clamps and reconnect the quick coupler to the explosion chamber to restore the test-gas purge route.

6. Proceed to the Test Gas Purge mode (Mode 4) and toggle "on" the switch labeled Inst Air. Conduct a five-minute purge of the explosion chamber to install the air environment that is required for this test.

7. Proceed to the Pulse mode (Mode 5). Insert the Shunt coil to bypass the Secondary Current meter. Set the time at "15" for approximately a 200-msec delay between powder dispersion and initiation of the capacitor discharge spark across the electrode gap (Table A-1). Set the capacitor bank charging potential to $100 \mathrm{~V}$ for $5 \mu \mathrm{f}$. Toggle "on" the Dispersion Disable switch in order to hold the sllde valve in the eloscd position. After observing that the Capacitor voltage meter has attained $100 \mathrm{~V}$, depress the Ready-Fire button and observe the spark discharge.

8. Allow thirty seconds for restoration of the charging potential, then toggle "off" the Dispersion Disable switch. Open the rotary valve. Depress the Ready-Fire button and observe the chronology of dust cloud formation and spark discharge. The optimum test conditlons will prevail when the leading edge of the cloud reaches the spark gap just as the spark is initiated. Adjust the Timer between $50-500 \mathrm{msec}$ (Table A-1) and the dispersing pressure between $7-10$ nsig as necessary to achievc llic optimum. Engage Pushhutton 1 to enter the Cleanup mode. Toggle the Probe Stop Release switch to the "on" position and rotate the vacuum probe crank counterclockwise

Table A-1

CALIBRATION OF ADJUSTABLE TIME DELAY FOR MINIMUM ENERGY DETERMINATION

\begin{tabular}{cr}
\hline $\begin{array}{c}\text { Dial } \\
\text { Setting }\end{array}$ & $\begin{array}{r}\text { Delayl1) } \\
\text { (msec) }\end{array}$ \\
\hline 5 & 50 \\
10 & 90 \\
15 & 200 \\
20 & 290 \\
25 & 350 \\
30 & 460 \\
35 & 500 \\
40 & 590 \\
45 & 650 \\
bu & 720 \\
\hline
\end{tabular}

(1) Approximate time interval between initiation of the dust cloud formation and electric spark pulsation across the electrode gap. to lower it into the explosion chamber. After cleaning is complete, retract the probe by a clockwise crank rotation until the counter dial reads 00025. (Caution: Cranking the vacuum probc assembly to a lower dial setting may result in disengagement of the chain-and-pulley mechanism.) Proceed to the Argon Purge mode (Mode 2) and toggle "on" the switch labeled Blended Gas. Turn the oxygen-mass flowmeter indicating switch to the "read" position and ascertain that the Inlet Valve control knoh is turned filly clockwise and that no oxygen flow is indicated. Turn the argon mass flowmeter indicating switch to the "read" position and slowly rotatc the Inlet valve control knob counterclockwise until the flowmeter dial indicator equilibrates at $1.0 \mathrm{scfm}$. Conduct a five-minute purge of the explosion chamber with pure argon to restore the ambient test-box environment.

9. Repeat this procedure (Steps 4 - 8) for the 2.0 and 3.0-gram samples. At the instant that the pressurized air is released into the explosion chamber, note the largest sample weight which is most completely removed from the dispersion cup. A belated observation of this event will be invalid, since the bulk of the sample will recollect in the cup. This weight 
should be employed for the $E_{m}$ determination unless the resulting dust cloud prevents spark visibility at $5 \mu \mathrm{f}$. If the latter occurs, the largest sample weight at which the spark is discernible should be designated as optimum. (d)

Minimum Energy Determination, $E_{m}$ - To determine $E_{m}$, observe the following steps:

1. Perform Steps 1-7, as outlined in the preceding procedure, while amending the procedure to employ the optimum sample weight, dispersing pressure, and time delay, but substituting a $100-\mu \mathrm{f}$ capacitance charged to a $100-\mathrm{V}$ potential.

2. Allow 30 seconds for restoration of the charging potential, then toggle "off" the Dispersion Disable switch. (Figure 1). Open the rotary valve. Depress the Ready-Fire button and observe the resulting dust cloud to determine whether a positive ignition has occurred. Propagation of a flame four inches or longer in the explosion chamber constitutes a positive ignition. (e) Should a positive ignition occur in at least one of four trials, proceed with Step 5. If not, follow Step 3.

3. Increase the capaoitance by increments of $20 \mu \mathrm{f}$, conducting up to two trials at each level until a positive ignition is obtained. Use the lowest capacitance required for positive ignition as the basis for calculation (see.Definitions and Calculations, 1a, Page 26, without attempting to obtain a closer determination. If no ignition is obtained in two trials at $160 \mu f$, proceed with Step 4.

4. After adjusting the electrode spark gap to $1 / 2 \mathrm{inch}$, charge a $20-\mu \mathrm{f}$ capacitor to $400 \mathrm{~V}$ and conduct one trial. Increase the capacitance by $50-\mu \mathrm{f}$ increments, conducting one trial at each level until a positive ignition is obtained. Calculate $E_{m}$ for a positive test according to Definitions and Calculations, 1b, Page 26. If no ignition is obtained in one trial at $160 \mu \mathrm{f}$, report $E_{m}$ as greater than 12.8 joules.

5. Should 'a positive ignition result from Steps 1 and 2 , proceed with repetitive determinations, reducing the capacitance by $10-\mu \mathrm{f}$ increments and conducting up to two trials at each level until both results are negative. Reduce the capacitance by $4-\mu f$ increments from that lowest value required for positive ignition until the minimum at which surh results develop in at least une of four trials is passed. Use this minimum capacitance as a basis for calculating $E_{m}$ according to 1 , Page 26, unless positive results are obtained at capacitances of less than $25 \mu \mathrm{f}$. If so, then proceed with Step 6 .

(d). The so-called upper explosion limit may be surpassed with excessive amounts of sample. This condition will result in the generation of insufficient heat from combustion in the proximity of the spark to raise the entire cloud to the ignition temperature. Flame propagation will also be reduced because of the presence of insufficient oxygen.

(e) In most cases, results should be positive at this level of spark energy. If not, three additional trials should be conducted, paying careful regard as to whether strict procedural conformity is being followed. 
6. Reduce the capacitance by $2-\mu \mathrm{f}$ increments from the lowest value required for positive ignition and conduct up to four trials at each level until the minimum at which such results develop in at least one of four trials is passed. Use this minimum capacitance as a basis for calculating $\mathrm{E}_{\mathrm{m}}$ according to 1a, Page 26.

Determining the Lower Explosion Limit (LEL) - To determine the LEL, follow these steps:

1. Close the main Power switch and allow the control console a warmup time of about five minutes (Figure 1). Engage Pushbutton 3 to enter the Load mode. Meanwhile, proceed with Steps 2 and 3. Secure the electrodes at the 4-inch level, then, adjust the electrode spark gap to 3/16 inch. Release the quick coupler at the explosion-chamber connection and remove the braided steel hose. Unlatch the lower explosion chamber clamps and turn the handcrank mechanism clockwise until the bellows assembly is sufficiently elevated to clear the tup sealing flange of the explosion s.hamber. Unilatch the rotary valve locking clamps and detach the explosion chamber from the disporsion cup. IIsing a short section of $1 / 4$-inch-! $n$ ruhber tubing, unthread the mushroom dispersion valve by two counterclockwise, 360-degree rotations from lis fully iriserted position, making sure that the stem and not the cap is unthreading.

2. Weigh a 1.00-gram sample onto powder paper. After conducting a ten-minute airlock purge, transfer the aliquot to the test box. The next operation (placement of the powder in the dispersion cup) is a most delicate and important operation, as it affects the quality of dispersion. Great care should be exercised to obtain a circular layer of uniform thickness. Within the toroidal layer, concentric to the mushroom dispersion valve, no portion of the bowl's surface should be exposed. This placement may best be accomplished by using a small, camel-hair brush mounted on a "Q-tip" applicator stick.

3. Set the dispersing pressure at 10 psig. Close the dispersion cup rotary valve. Attach the explosion chamber and secure the locking clamps. Insert the exterided tips of each of the electrodes into the bore of the lead connectors. Using the perforator tool, make a $1 / 16$-inch hole in the center of the blowout diaphragm, place it between the top sealing flange of the explosion chamber and the lower bellows assembly sealing surface, and lower the assembly by counterclockwise rotation of the handcrank mechanism. Secure. the lower expansion chamber clamps and reconnect the quick coupler to the expansion chamber to restore the test-gas purge route.

4. Proceed to the Test Gas Purge mode (Mode 4) and toggle "on" the switch labeled Inst Air. Conduct a five-minute purge of the explosion chamber to install the air environment that is required for this test.

5. Proceed to the Steady mode (Mode 6). Detach the Shunt çoll to platu the Secondary Current meter in circuit. Toggle "on" the Dispersion Disable switch in order to hold the slide valve in the "closed" position during test firings. Depress the Ready-Fire button and adjust the High Voltage Control for $231 \mathrm{ma}$. This current should be generated by about a $90-\mathrm{V}$ primary voltage. After allowing the electrodes to cool for about 30 seconds, open the rotary valve. Togyle "off" the Dispersion Disable switch. Depress the Ready-Fire button and observe the resulting dust cloud for its explosive behavior. A positive test has resulted when a well-defined, low-order explosion occurs instantaneously and is of sufficient severity to rupture the blowout diaphragm. 
Careful scrutiny of this event is necessary to avoid a possible misinterpretation. A positive test has resulted only when the blowout diaphragm ruptures immediately upon flame propagation. This action should occur with the development of a suddenly applied explosion pressure of about $21 / 2$ psig. Under these conditions, the diaphragm will usually tear completely away. However, even partial tearing or a burn through of the diaphragm because of flame propagation constitutes a rupture. Ignition, flame propagation, and legitimate rupture should occur within three seconds after depression of the Ready-Fire button. Subsequent rupturing will be due to powder clogging the pores of the diaphragm and does not constitute a positive test. (In most cases, results should be positive at this dispersed-dust-cloud concentration.) Should such explosion behavior not occur, three additional trials should be conducted. If a positive test occurs in at least one of four trials, proceed with Steps 6, 9, and 10. If not, follow Steps 6 - 8.

6. Engage Pushbutton 1 to enter the Cleanup mode. Toggle the Probe Stop Release switch to the "on" position and rotate the vacuum probe crank counterclockwise to lower it into the explosion chamber. After cleaning is complete, retract the probe by a clockwise crank rotation until the counter dial reads 00025. (Cautinn: r.ranking the vacuum probe assembly to a lower dial setting may result in disengagement of the chain-and-pulley mechanism.) Proceed to the Argon Purge mode (Mode 2) and toggle "on" the switch labeled Blended Gas. Turn the oxygen mass flowmeter indicating switch to the "read" position and ascertain that the Inlet Valve control knob is turned fully clockwise and that no oxygen flow is indicated. Turn the argon mass flowmeter indicating switch to the "read" position and slowly rotate the Inlet Valve control knob counterclockwise until the flowmeter dial indicator equilibrates at $1.0 \mathrm{scfm}$. Conduct a five-minute purge of the explosion chamber with pure argon to restore the ambient test-box environment.

7. Increase the sample weights by increments of $0.25 \mathrm{gram}$, conducting up to two trials at each level until a positive test is obtained or until both results are negative for 2.00-gram samples. In case of the former, use this minimum weight as the basis for the LEL calculation according to Definitions and Calculations, 2b, Page 27 without attempting a closer determination. If the latter results, proceed with Steps 6 and 8.

8. Increase the sample weights by increments of 0.5 gram, conducting one trial at each weight until a positive test is obtained, or until no such result is obtained by using the largest sample weight which may be completely dispersed from the sample cup while retaining spark visibility. In case of the former, use the same reporting basis as outlined in Step 7 for calculating the LEL. If the latter results, report the LEL as greater than the highest readily dispersible concentration.

9. Decrease the sample weights by increments of $0.20 \mathrm{gram}$, conducting two trials at each level until both tests are negative. Reduce the sample weight by 0.05 -gram increments from the lowest level required for a positive test until the minimum at which such results occur in at least one of four trials is passed. Use this minimum weight as a partial basis for the LEL calculation, according to 2a, Page 27, and proceed with Step 11 unless positive results are obtained at or below 0.20-gram samples. If so, proceed with Step 10. 
10. Reduce the sample weight by 0.025 -gram increments from the lowest level required for a positive test until the minimum at which such results occur in at least one of four trials is passed. Use this minimum weight as a partial basis for the LEL calculation, according to 2a, Page 26, and proceed with Step 11.

11. Secure the electrodes at the 2-inch level. Repeat Steps $1-6$, using that dispersing pressure between 6 and 10 psig which produces most complete and uniform dispersion, but substituting that minimum weight as determined in Step 9 or 10 for initial trials. Conduct up to four trials using this weight. If a positive result is obtained, reduce the sample weight in 0.05-gram increments, or in 0.025-gram increments if Step 10 has been employed until the minimum at which results occur in at least one of four trials is passed. Use this minimum weight at which a positive result is obtairied along with results from Sten 9 or 10 as a basis for calculating the LEL. If all rosults are negative. proceed witli Step 12.

12. Increase the sample weights in increments of 0.20 gram, conducting up to two trials at each level until a positive test is obtained or until both results are negative for $1.00 \mathrm{gram}$ samples. In case of the former, reduce the sample weight by 0.05 -gram increments from that lowest level required for a positive test until the minimum at which such results develop in at least one of four trials is passed. Use this minimum weight and that obtained from Step 9 or 10 as the basis for calculating the LEL. If the latter occurs, use the $>1.00$-gram weight and that obtained from Steps 9 and 10 as the basis for the LEL calculation.

\section{Determining the Limiting Uxygen Content (LOC) -}

Explosion Prevention - For establishing explosion limits, observe the following procedure:

1. Close the main Power switch and allow the control console about five minutes to warm up (Figure 1). Engage Pushbutton 3 to enter the Load mode. Meanwhile, proceed with Steps 2 and 3. Secure the electrodes at the 4-inch level; adjust the electrode spark gap to $3 / 16$ inch. Release the quick coupler at the explosion-chamber ronnection and remove the bralded steel liuse. Uniateh the lower explusion chamber clamps and turn the handcrank mechanisısı clockwise until the bellows assembly is sufficiently elevated to clear the top sealing flange of the explosion chamber. Unlatch the rotary-valve locking clamps and detach the explosion chamber from the dispersion cup. Using a short section of $1 / 4$-inch-1D rubber tubing, unthread the mushroom dispersion valve by two counterclockwise 360-degree rotations from its fully inserted position, making sure that the stem and not the cap is unthreading.

2. Refer to Page 20 (Step 8) for the optimum sample size, and weigh this quantity into plastic vials. After conducting a ten-minute airlock purge, transfer the aliquot to the test box. Spread the sample as uniformly as possible in the dispersion cup, leaving vacant the area within an $1 / 16$-inch radius of the periphery of the mushroom valve. 
3. Set the dispersing pressure at 10 psig. Close the dispersion-cup rotary valve. Attach the explosion chamber and secure the locking clamps. Insert the extended tips of each of the electrodes into the bore of the lead connectors. Using the perforator tool, make a 1/16-inch hole in the center of the blow-out diaphragm and place it between the top sealing flange of the explosion chamber and the lower bellows assembly sealing surface and lower the assembly by counterclockwise rotation of the handcrank mechanism. Secure the lower expansion chamber clamps and reconnect the quick coupler to the expansion chamber to restore the test-gas purge route.

4. Proceed to the Test Gas Purge mode (Mode 4) and toggle "on" the switch labeled Blended Gas. Turn the argon mass flowmeter indicating switch to the "read" posiliun and slowly rotate the Inlet Valve control knob counterclockwise until the flowmeter dial indicator equilibrates at $0.8 \mathrm{scfm}$. Do the same for the oxygen mass flowmeter until the dial indicator equilibrates at 0.20 scfm. These flows will provide an 80:20 volume ratio of argon and oxygen. Conduct a five-minute purge of the explosion chamber to install this environment.

5. Proceed to the Steady mode (Mode 6). Detach the Shunt coil to place the Secondary Current meter in circuit. Toggle "on" the Dispersion Disable switch in order to hold the slide valve in the closed position during test firings. Depress the Ready-Fire button and adjust the High-Voltage Control for $23.1 \mathrm{ma}$. This current will be generated by about a $90 . \mathrm{V}$ primary voltage. After allowing the electrodes to cool for about 30 seconds, open the rotary valve. Toggle "off" the Dispersion Disable switch. Depress the Ready-Fire button and observe the resulting dust cloud for its explosive behavior. The same criteria for a positive test should be employed as for the lower explosion limit (LEL) determination (Page 22). Results should be positive at this oxygen-argon level if positive LEL results were obtained. If not, proceed with Step 6, then check all operating parameters, and review procedures. After positive results are obtained, proceed with Steps 6 and 7.

6. Engage Pushbutton 1 to enter the Cleanup mode. Toggle the Probe Stop Release switch on the "on" position and rotate the vacuum probe crank counterclockwise to lower it into the explosion chamber. After cleaning is complete, retract the probe by a clockwise crank rotation until the counter dial reads 00025 . (Caution: Cranking the vacuum probe assembly to a lower dial setting may result in disengagement of the chain-and-pulley mechanism.) Proceed to the Argon Purge mode (Mode 2) and toggle "on" the switch labeled Blended Gas. Turn the nxygen mass flowmeter iindicaling swltch to the "read" position and ascertain that the Inlet Valve control knob is turned fully clockwise and that no oxygen flow is indicated. Turn the argon mass flowmeter indicating switch to the "read" position and slowly rotate the Inlet Valve control knob counterclockwise until the flowmeter indicator dial equilibrates at $1.0 \mathrm{scfm}$. Conduct a five-minute purge of the explosion chamber with pure argon to restore the ambient lest-box environment. 
7. Repeat Steps $1-3$, then proceed to the Test Gas Purge mode (Mode 4) and toggle "on" the switch labeled Blended Gas. Set the argon flow at $0.85 \mathrm{scfm}$ and the oxygen flow at $0.15 \mathrm{scfm}$ as detailed in Step 4. Conduct a five-minute test-gas purge, then proceed to the Steady mode (Mode 6) and repeat the explosibility test. If positive results occur in one of four trials, proceed with Step 8; if not, report the limiting oxygen content as 15.0 percent by volume (Item 3a, Page 27).

8. Repeat Step 7-except for employing oxygen-argon flows of 0.10 and $0.90 \mathrm{scfm}$ for the test-gas purge. If positive results occur in one of four trials, proceed with Step 9; if not, report the limiting oxygen as 10.0 percent by volume (3a, Page 27).

9. Proceed to roduce the oxygen concentration in increments of two percent, and otherwise repeat Step 7 until test results are negative in four of four trials. Proceend with Step 10.

10. Increase the oxygen concentration by one percent above that value for which negative results were obtained in four of four trials in Step 9, and repeat Step 7. If positive results occur in one of four trials, report the limiting oxygen content according to the findings of Step 9; if results are negative in four of four trials, report the limiting oxygen content as the volume percentage employed for this trial (3a, Page 27).

Ignition Curtailment - Employing, initially, the lowest oxygen concentration at which positive results were obtained and the test parameters established therein, repeat that procedure except define a pusitive test as flame propagation one inch or longer within the dispersed dust cloud. Calculations are made according to Definitions and Calculations, Item 3b, Page 27.

Definitions and Calculations - Certain terms need to be defined and calculations made in these procedures:

1. Minimum energy required for ignition of a dist cloud. The minlmum tirergy, $E_{111}$ is defined as the smallest capacitor discharge spark energy required to produce flame propagation four inches or longer in a dust cloud of optimum conrentration. $E_{m}$ in millijoules (mj) is determined by the following relations where $\mathrm{C}$ is the capacitance in microfarads:

a. At a $100-\mathrm{V}$ capacitor charging potential:

$$
E_{m}=5 \times C .
$$

b. At a $400-\mathrm{V}$ capacitor charging potential:

$$
E_{m}=80 \times C
$$


2. Lower explosion limit of a dispersed dust cloud. The lower explosion limit (LEL) is the smallest sample weight which may be ignited by induction spark to produce a low-ordered explosion of an established magnitude within an enclosed volume.

a. The minimum sample weights required for explosion when the electrodes are placed at the 2 and 4 -inch levels $\left(\mathrm{M}_{2}\right.$ and $\left.\mathrm{M}_{4}\right)$ are averaged and expressed in terms of the explosion chamber volume $(1.23 \ell)$ as the LEL in grams per liter:

$$
L E L=\frac{M_{2}+M_{4}}{2 \times 1.23}=\frac{M_{2}+M_{4}}{2.46}
$$

b. When only the 4-inch level is employed:

$$
L E L=\frac{M 4}{1.23}
$$

3. Limiting oxygen oontent (LOC) irivulves two considerations:

a. Explosion Prevention. This value is the highest environmental oxygen content at which explosion or rapid combustion does not occur in four of four trials using the optimum dispersed dust concentration and a continuous induction spark in a predominantly argon atmosphere.

b. Ignition Curtailment. This value is the highest environmental oxygen content at which flame propagation one inch or longer does not occur in four of four trials using the optimum dispersed dust concentration and a continuous -induction spark in a predominantly argon atmosphere.

Both values are computed as follows:

$$
V \% O x=\frac{R_{O x}}{R_{O x}+R_{A r}} \times 100
$$

where:

V\%Ox represents the percent by volume of oxygen,

$R_{0 x}$ the oxygen flow in scfm, and

RAr the argon flow in scfm.

\section{Discussion}

The general test procedure now employed entails the dispersion of a weighed quantity of dust within an explosion chamber by a single blast of air with its almost simultanenus exposure to an igniting source. The top of the chamber (see Figure 1) is covered by a 
permeable blowout diaphragm which bursts from a suddenly applied pressure of about $21 / 2$ psig. All dust dispersions are essentially static. Definitions of a positive test vary, depending on the nature of the determination (see Page 26). The instrument described herein closely correlates with its counterpart at the Bureau at dispersing pressures $\leqslant 10 \mathrm{psig}$, according to the check analyses results (Tables A-2 and A-3) so that certain comparisons within these limits may be validly drawn. In order to insure that this correlation is maintained, periodic checks should be made using the specified standards (see Equipment Used, Page 18).

A complete evaluation usually requires about 100 grams of the powder. Upon receipt of a powder sample at the Laboratory, its history should be ascertained. Past difficulties experienced in its handling due to extreme ignition sensitivity or suspected pyrophoricity should be documented. The sample should be placed immediatcly in the dry argon storage facility sn that its as-recelved integrity may be maintained prior to testing. It is suggested that the Laboratory issue its findings to the requestor in a briel vuritten report. Thic

Table A-2

COMPARATIVE EXPLOSIBILITY RESULTS FOR A STANDARD

PITTSBURGH COAL DUST

(Bureau Sample 2551)

MINIMUM ENERGY $\left(E_{m}\right)(1)$

\begin{tabular}{|c|c|c|c|c|c|c|}
\hline \multirow[b]{2}{*}{ Trial } & \multirow{2}{*}{$\begin{array}{l}\text { Dispersing } \\
\text { Air Prcssure } \\
\text { (psig) }\end{array}$} & \multicolumn{2}{|c|}{$\begin{array}{c}\text { Optimum Delay } \\
\text { Between Powder } \\
\text { Dispersion and } \\
\text { Spark Pulsation } \\
\text { (msec) }\end{array}$} & \multicolumn{2}{|c|}{$E_{m}{ }^{(2)}$} & \multirow{2}{*}{$\begin{array}{c}\text { Percent } \\
\text { Difference }\end{array}$} \\
\hline & & $Y-12$ & $\mathrm{BM}$ & $Y-12$ & $\mathrm{BM}$ & \\
\hline 1 & 5 & 594 & 580 & 325 & 340 & - 4.1 \\
\hline 2 & 6 & 206 & 110 & 335 & 340 & $\cdot 1.5$ \\
\hline 3 & 9 & 415 & 425 & 340 & 340 & - \\
\hline 4 & 10 & 206 & 190 & 340 & 340 & - \\
\hline 5 & 11 & 380 & 365 & 285 & 340 & -16.0 \\
\hline 6 & 12 & 294 & 110 & 270 & 360 & -25.0 \\
\hline
\end{tabular}

LOWEH EX'PLOSION LIMIT (LEL) (3)

\begin{tabular}{|c|c|c|c|c|c|c|}
\hline \multirow[b]{2}{*}{ Trial } & \multirow{2}{*}{$\begin{array}{c}\text { Dispērssing } \\
\text { Alr Pressure } \\
\text { (nsig) }\end{array}$} & \multirow{2}{*}{$\begin{array}{c}\text { 3porle } \\
\text { Level (4) } \\
\text { (in) }\end{array}$} & \multirow{2}{*}{$\begin{array}{c}\text { Flertrnde } \\
\text { Spark Gap } \\
\text { (in) }\end{array}$} & \multicolumn{2}{|c|}{$\begin{array}{c}\text { LEL } \\
\text { (gm/l) }\end{array}$} & \multirow{2}{*}{$\begin{array}{c}\text { Pelceitl } \\
\text { Difference }\end{array}$} \\
\hline & & & & $Y .12$ & $\mathrm{BM}$ & \\
\hline 7 & 14 & 4 & $3 / 16$ & 0,069 & 0.061 & 13.1 \\
\hline 8 & 13 & 4 & $1 / 4$ & 0.081 & 0.061 & 32.8 \\
\hline 9 & 5 & 2 & $1 / 8$ & 0.061 & 0.065 & -6.1 \\
\hline 10 & 7 & 2 & $3 / 16$ & 0.057 & 0.053 & 7.5 \\
\hline 11 & 7 & 2 & $1 / 4$ & 0.053 & 0.053 & . \\
\hline
\end{tabular}

(1) The smallest capacitor discharge spark energy required to produce flame propagation four inches or longer, in a dust cloud of optimum concentration.

(2) Using 3.0-gm sample weights and a 1/8-incti electrode spark gap.

(3) The smallest sample weight which may be ignited by induction spark to produce a low-ordered explosion of an established magnitude within an enclosed volume.

(4) The height of electrode placement in the explosion chamber. 
Table A-3

COMPARATIVE EXPLOSIBILITY RESULTS FOR

A STANDARD ALUMINUM DUST

(Atomized Commercial Purity Fines)

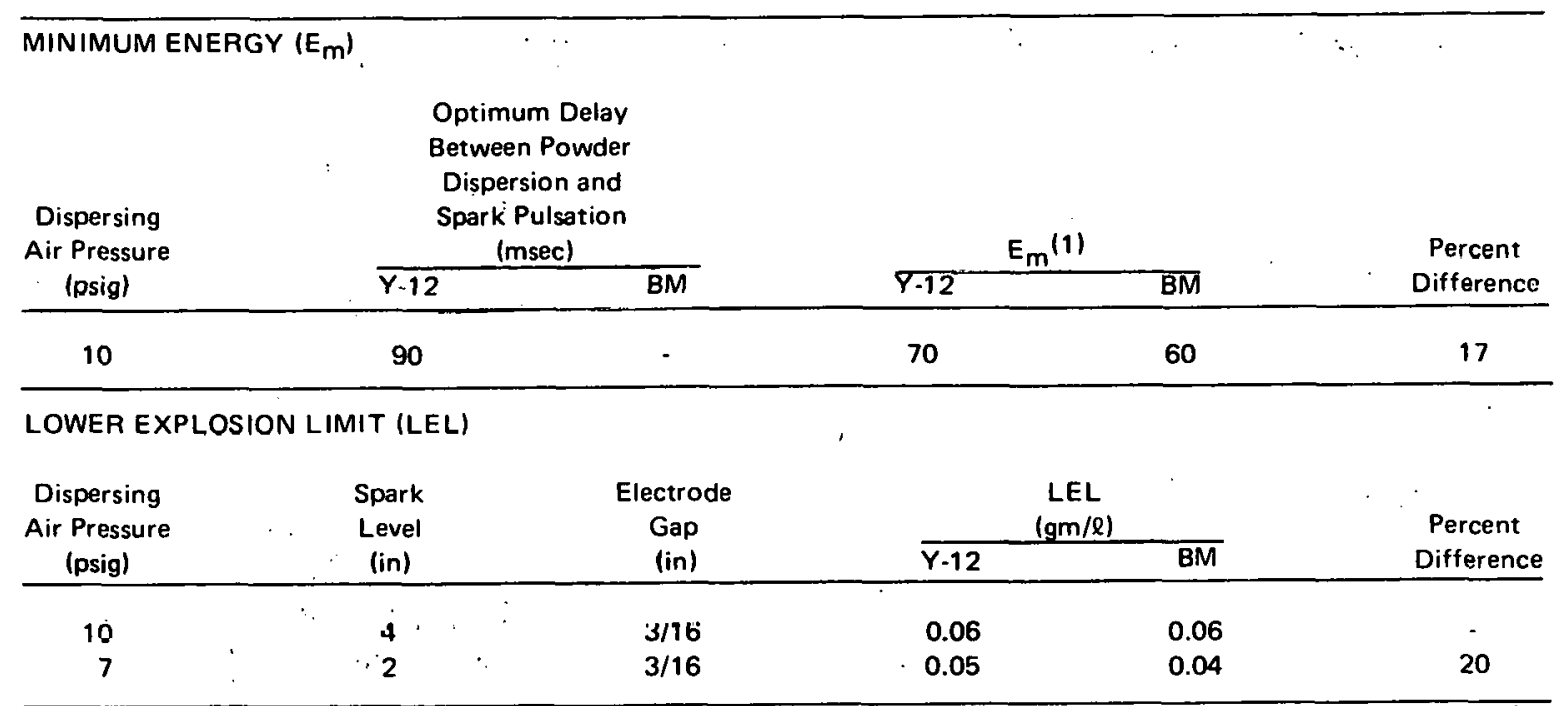

(1) Using 1.0-gram sample weights and a $1 / 8$-inch electrode spark gap.

memorandum should include a statement relating the type of sample tested, sample history, tabulated results with test definitions, and some interpretative statements. A particle-size distribution, surface area, and oxygen content for each sample should be reported as supplementary information pertinent to its ignitability and/or explosibility characteristics. Cautious discretion should be exercised in interpreting the $L E L$ and $E_{m}$ results. These tests serve only to define the propensity for igntion or explosion relative to other materials, but such information when referenced to the standard Pittsburgh seam coal dust is useful for comparative purposes and should routinely be obtained and reported. Recommendations for safe powder handling procedures should be based solely on the LOC determinations. 


\section{DISTRIBUTION}

Atomic Energy Commission - ORO

Hickman, H. D.

Zachry, D. S., Jr

\section{Oak Ridge Gaseous Diffusion Plant}

Wilcox, W. J., Jr

Winkel, R. A.

\section{Oak Ridge Y-12 Plant}

Barkman, J. R.

Bentley, E. L.

Bernander, N. K.

Blackman, J. T.

Briscon, n.W.

Burditt, R. B.

Burkhart, L. E.

Carden, W. F.

Choat, E. E.

DeMuribrun, J. R.

Denny, A. (2)

Dodson, W. H.

Hackett, U. W.

Hemphill, L. F.

Hensley, C. E.

Johnson, C. E.

Innes, F. W.

Kahl, K. G.

Keith, Alvin

Litt!le, .I. C.

Lore, J. D. (2)

Marrow, $\cap R$.

McLendon, J. D.

Miller, J. E. (2)

Mitchel, G. W.

Morehead, J. F.

Rowan, J. H.
Scalf, C. L.

Schreyer, J. M.

Sissom, D. T.

Smith, H. F., Jr

Smith, R. D.

Tewes, W. E.

Thompson, W. H.

Trotter, T. C.

Weathersby, W. E.

Williams, R. D.

Yaggi, W. J.

Y-12 Central Files (5)

$Y=12$ Contral Files (master isipy)

$Y-12$ Central Files (route)

$Y-12$ Central Files (Y-12RC)

Paducah Gaseous Diffusion Plant

In addition, this document is distributed in accordance with the category UC-38,

Engineering and Equipment, as given in the USAEC Standard Distribution Lists for Unclassified Scientific and Technical Reports, TID-4500. 